\title{
LECTURA: COMPRENSIÓN VS. RETENCIÓN DE INFORMACIÓN. UNA INTERPRETACIÓN COGNITIVA
}

\author{
Alicia Massone y Gloria Gonzalez \\ Universidad Nacional de Mar del Plata
}

\section{INTRODUCCIÓN}

La lectura es una actividad cognitiva que no se agota en la decodificación de un conjunto de grafías y en su pronunciación correcta, conlleva la necesidad de comprender aquello que se lee, esto es, la capacidad de reconstruir el significado global del texto. En consecuencia, estamos en condiciones de afirmar que nuestro objeto de estudio refiere a una acción intelectual de alto grado de complejidad bajo el supuesto de que el que lee debería poder elaborar un significado del texto que, a su vez, contemple el que le dio el autor. La lectura es una actividad múltiple. Cuando leemos, y comprendemos lo que leemos, nuestro sistema cognitivo identifica las letras, realiza una transformación de letras en sonidos, construye una representación fonológica de las palabras, accede a los múltiples significados de ésta, selecciona un significado apropiado al contexto, asigna un valor sintáctico a cada palabra, construye el significado de la frase para elaborar el sentido global del texto y realiza inferencias basadas en su conocimiento del mundo. La mayoría de estos procesos ocurren sin que el lector sea consciente de ellos; éstos son muy veloces, pues la comprensión del texto tiene lugar casi al mismo tiempo que el lector desplaza su vista sobre las palabras.

Existe, asimismo, acuerdo en que la educación formal pocas veces se ocupa de enseñar la comprensión, más bien es una demanda que se le plantea al estudiante que debe "comprender" o "entender". Según Piacente (2003), existe consenso en que una proporción significativa de estudiantes tienen dificultades para leer y escribir, no se trata de déficit inherentes al reconocimiento de palabras sino de dificultades asociadas a movilizar conocimiento previos implícitos, y al tipo de procesamiento implicado.

En nuestra investigación, se procedió a evaluar problemas vinculados a las temáticas antedichas, por lo que se apeló a la selección de textos académicos específicos, pero heterogéneos en cuanto a su naturaleza, a los que cabría atribuirles un grado medio de complejidad. El propósito de la tarea era indagar acerca del tipo de procesamiento utilizado privilegiadamente por los egresados de nivel medio, su familiaridad con escritos propios del quehacer científico y la formación alcanzada en relación con las habilidades y estrategias de lectura y escritura, entre otros. El impacto que se presume se relaciona con la detección de aquellas dificultades prevalentes para luego estar en condiciones de proponer y/o desarrollar estrategias de intervención que puedan mejorar el rendimiento académico de los alumnos.

\section{POBLACIÓN}

Se trabajó con una muestra de 178 egresados de Polimodal, de la ciudad de Mar del Plata. Argentina, pertenecientes a escuelas de gestión publica y privada, de ambos sexos, cursantes de turnos mañana y tarde y provenientes de diversas orientaciones. 


\section{PROCEDIMIENTO}

Para evaluar comprensión lectora y retención de información se administró una prueba de evaluación conformada por dos textos de distinta tipología:

Texto 1 : se trata de un texto narrativo. El objetivo de la prueba es valorar la capacidad de los alumnos para captar el argumento básico del texto y recordar detalles del mismo.

Texto 2: se trata de un texto expositivo, similar al que se podría encontrar en un libro de texto. El objetivo de la prueba es valorar si son captadas las ideas principales y los hechos más importantes descritos en el texto.

\section{RESULTADOS}

Los egresados de Polimodal que participaron del estudio, manifiestan diferencias considerables entre los puntajes medios obtenidos en retención de información 7.36 puntos sobre un puntaje máximo de 10 puntos. Con respecto al puntaje obtenido en comprensión de texto nuestros estudiantes alcanzaron 4.77 puntos sobre un máximo de 10 puntos.

Observamos una amplia diferencia de rendimiento entre la capacidad de comprensión y la de retención, este resultado fue sorprendente puesto que a rivel cognitivo se espera que la retención de información se asocie a la comprensión, es decir, que cuanto más se comprende más se retiene aquello que estamos aprendiendo.

A partir de estos resultados, cabe sostener que procesos que se suponen asociados como retención y comprensión no se estarían comportando asociadamente en el caso en estudio. Es decir, se hallaron sujetos con puntuaciones bajas en comprensión que obtuvieron puntuaciones altas en retención de información. Para el caso inverso, el fenómeno ro parece frecuente ya que sólo dos sujetos obtuvieron puntuaciones altas en comprensión y bajas en retención. Lo antedicho podría atribuirse a que, desde el punto de vista cognitivo, la comprensión implica un proceso cognitivo de elaboración o profundo (macroproceso) mientras que la retención sólo requiere un proceso superficial (microproceso).

Para concluir, el puntaje más frecuente obtenido en esta población para comprensión de texto fue de 6/10 puntos mientras que en retención el puntaje más frecuente fue de 8.5/10.

\section{CONCLUSIONES}

En líneas generales el dato más revelador y que, a nuestro modo de ver, debería ser especial y prioritariamente atendido es el grado de dificultad encontrado en la comprensión de lo que se lee, máxime que es esta misma cohorte la que en el corto plazo estará expuesta a la interacción con textos académicos de una mayor densidad teórica.

También queremos destacar las dificultades que presentan para expresar por escrito sus ideas. Este fenómeno, aparece ligado a los déficit para expresarse con coherencia tanto semántica como gramaticalmente, a lo que debe añadirse la frecuencia con que se registran problemas ortográficos que no dejan de sorprender para el caso de sujetos que vienen de finalizar su educación media o polimodal 
Con respecto a lo que se ha dado en llamar retención de información los resultados obtenidos son más alentadores con respecto a los que venimos haciendo referencia. Sin embargo, cabría preguntarse acerca de las implicancias de que, precisamente, los mejores resultados se obtengan en un área donde prevalece la memoria a corto plazo y el tratamiento superficial de la información.

\section{BIBLIOGRAFÍA}

BAllesteros, S. (1996) Practicas de Psicología Básica. Universitas.

PiAcente, T. TItARELl, A. (2003) ¿ Alfabetización Universitaria ? UBA X Jornadas de Investigación, pp. 290 . 


\title{
Contactar
}

Revista lberoamericana de Educación

\author{
Principal OEI
}

